\title{
Histopathological Diagnosis of Non-Alcoholic and Alcoholic Fatty Liver Disease
}

\author{
Andrea Tannapfel and Berenike Flott-Rahmel \\ Institute of Pathology, \\ Ruhr-University Bochum, \\ Germany
}

\section{Introduction}

Fatty liver is a common 'liver disease' often free of symptoms or complaints but might even lead to severe stages. It is characterized by lipid deposition in hepatocytes both, for alcoholic as well as and non-alcoholic fatty liver. An additional inflammatory reaction results in - alcoholic (ASH) or non-alcoholic (NASH) - steatohepatitis. Steatohepatitis is characterized by both, inflammatory infiltrates of mixed cells in the small liver lobules as well as liver cell injury in terms of ballooning. NASH resembles alcoholic liver disease, but occurs in people who consume little or no alcohol. Many people with NASH don't feel sick and are not aware of their liver problem. Nevertheless, NASH can get severe and can result in cirrhosis with permanent tissue damage.

It has long been known that the typical manifestations of alcoholic liver damage (including cirrhosis of the liver) can also be found in patients who consume no alcohol. For such persons the incorrect diagnosis of 'alcohol-related liver disease' on the basis of just histopathological findings can have grave social, legal, and insurance implications.

The term 'non-alcoholic steatohepatitis' (NASH) was established by Ludwig et al. in 1980. The terminology was later expanded (Bacon et al., 1994). Patients were described who manifested the typical histomorphological pattern of alcoholic steatohepatitis (ASH), but without or with only moderate alcohol consumption (Ludwig et al., 1997).

Diagnosis by means of biopsy is the gold standard for differentiation between reversible steatosis and progressive steatohepatitis. There are numerous publications on this topic with the aim of developing uniform standards for biopsy diagnosis or identifying reliable noninvasive or only slightly invasive alternatives to biopsy, particularly driven by the increasing prominence of alcoholic and non-alcoholic steatohepatitis.

The term non-alcoholic fatty liver (NAFL) is not restricted to adults but also used to describe the same condition in children and adolescents (Baumann, 2005). Accordingly, the term nonalcoholic steatohepatitis (NASH) is used in the paediatric age group for the more aggressive form of hepatocellular degeneration accompanied by fibrosis (Rashid \& Roberts, 2000; Roberts, 2002). People at increased risk of developing a fatty liver, as well possess an increased risk of developing chemotherapy-associated steatohepatitis (CASH).

Diagnostic procedures in patients with suspected fatty liver disease should be standardized and generally accepted. The goal of this chapter is thus to delineate the current concepts of aetiology, diagnostic as well as differential diagnostic of patients with fatty liver disease 
with regard to the pathohistological diagnosis and to provide expert assessment of the noninvasive alternatives.

The present book chapter is adapted from the German Leitlinie 'Histopathologische Diagnose der nichtalkoholischen und alkoholischen Fettlebererkrankung' (Tannapfel et al. 2009), under the auspieces of the 'Deutsche Gesellschaft für Pathologie', and under participation of the 'Deutsche Gesellschaft für Verdauungs- und Stoffwechselerkrankungen (DGVS) ', the 'Deutsche Diabetes Gesellschaft (DDG), the Berufsverband Deutscher Pathologen, the 'Kompetenznetz Hepatitis (HepNet) ', the 'Gesellschaft für Pädiatrische Gastroenterologie und Ernährung (GPGE) ', the 'Österreichische Gesellschaft für Pathologie (ÖGP) ', the 'Österreichische Gesellschaft für Gastroenterologie und Hepatologie (ÖGGH) ', the 'Schweizerische Gesellschaft für Pathologie (SGPath)'.

\section{Definitions and diagnostic criteria}

\subsection{Definitions}

An alcoholic (AFL) and a non-alcoholic fatty liver (NAFL) characteristically show variable amounts of lipid deposition - principally triglycerides - in hepatocytes. Involvement of more than $5 \%$ of hepatocytes is termed 'fatty degeneration'. If more than $50 \%$ of these cells are affected a 'fatty liver' is present. A subsequent inflammatory reaction with ballooning of the hepatocytes results in steatohepatitis.

NASH resembles alcoholic liver disease, but occurs in people who drink little or no alcohol. The major feature in NASH is fat in the liver, along with inflammation and damage. NASH can be severe as ASH and may lead to fibrosis or cirrhosis, in which the liver is permanently damaged.

Light-microscopically detectable deposition of lipid droplets in the cytoplasm of hepatocytes is termed steatosis. Microvesicular and macrovesicular steatosis can be distinguished; mixed forms occur (Burt et al., 1998). For the accumulation of fat in the liver four pathogenetic processes are responsible: 1 . Increased uptake of free fatty acids via the portal vein (from food or body fat), 2. Increased synthesis of free fatty acids in the liver (from glucose or acetate), 3. Decreased $\beta$-oxidation of free fatty acids, 4 . Decreased synthesis or secretion of very low density lipoproteins (VLDL) the pathway for elimination of lipids from the liver (Burt et al., 1998).

In the past, alcohol was usually suspected as the cause of steatosis. However, steatosis frequently can be observed in adiposity, diabetes mellitus type II and hyperlipidaemia components of the so-called "Metabolic Syndrome". Moreover, other factors such as toxins, medications, congenital metabolic disorders (e.g. a-beta-lipoproteinaemia/hypobetalipoproteinaemia), hormonal imbalances (as observed in polycystic ovary syndrome) or other to date unknown causes may lead to steatosis (Church et al., 2006; Dancygier, 2006; Farrell\& Larter, 2006). The morphological spectrum of non-alcoholic fatty liver disease (NAFLD) stretches from simple steatosis over steatohepatitis to liver fibrosis and cirrhosis, and thus ultimately to hepatocellular carcinoma. While pure steatosis is in principle reversible, steatohepatitis represents the progressive lesion in this spectrum.

NAFLD is thought to be the most frequent liver disease in the western industrial nations and thus the commonest cause of elevated transaminases. The diagnosis of NAFLD is made on basis of clinical (exclusion of significant alcohol consumption) combined with histopathological (demonstration of steatosis or steatohepatitis) findings. Significant alcohol consumption is defined as more than $20 \mathrm{~g}$ alcohol per day in women and as more than 40 g/day in men (Brunt, 2001; Neuschwander-Tetri \& Caldwell, 2003). 
The prevalence of NAFL in the western industrial nations is assumed to be $20-30 \%$, that of NASH 2 - 3\% (Cortez-Pinto et al., 2006; Dancygier, 2006; Day, 2006). There is a direct relationship with body weight: In obesity (BMI $>30)$ the prevalence of sonographically detectable steatosis is $76-89 \%$, compared with $46-50 \%$ in alcoholics (Bellentani et al., 2004). NAFLD is increasingly being diagnosed in childhood, again predominantly in association with obesity, but occasionally with suprasellar tumours (Alfire \& Treem, 2006).

The natural course of NAFLD in the individual case cannot be predicted. Only a small proportion of those affected show progression of their liver disease. The assumption is that simple steatosis will progress to NASH in around $10-20 \%$ of patients, and that of these, less than 5\% will develop cirrhosis (Day, 2006; Kacerovsky \& Roden, 2007; Mendez-Sanchez et al., 2007). Nevertheless, NAFL and NASH are currently believed to be the most important cause of so-called cryptogenic cirrhosis of the liver (Farrell\& Larter, 2006; Caldwell et al., 1999).

The pathogenesis of NASH remains unclear. In the so called "two-hit" hypothesis, accumulation of free fatty acids and triglycerides in the liver (simple steatosis) represent a first hit, rendering the organ more vulnerable to a second hit that leads to steatohepatitis and ultimately, in the event of persisting or recurring damage, to fibrosis and cirrhosis (Day \& James, 1998; Day, 2002).

Insulin resistance seems to play a central part (Chitturi et al., 2002). It can be observed in virtually all patients. As a consequence of elevated peripheral lipolysis and decreased glucose uptake by the musculature, uptake of free fatty acids from the bloodstream rises. This leads to an increase in hepatic triglyceride synthesis and simultaneous inhibition of triglyceride secretion in the form of VLDL as a result of decreased apoprotein synthesis. The increase in the hepatic pool of free fatty acids leads to a rise in mitochondrial and peroxisomal $\beta$-oxidation with formation of reactive oxygen species (ROS), and thus to oxidative stress and increased lipid peroxidation. Facilitated by the action of proinflammatory cytokines (via activation of $\mathrm{NF}-\kappa \mathrm{B}$, release of $\mathrm{TNF} \alpha$ ), steatohepatitis develops. Via Kupffer cell activation, liver fibrosis or cirrhosis arises (Farrell \& Larter, 2006; Neuschwander-Tetri \& Caldwell, 2003; Cortez-Pinto et al., 2006; Kacerovsky \& Roden, 2007; Mendez-Sanchez et al., 2007; Duvnjak et al., 2007; Edmison \& McCullough, 2007; Medina et al., 2004). The possible direct or indirect (increased insulin resistance) role of the adipocyte hormones (leptin and adiponectin) in the pathogenesis of NASH remains largely unclear. Another factor still discussed is the influence of bacterial overgrowth in the small intestine with endogenous production of ethanol and possible direct cytokine activation (Dancygier, 2006; Edmison \& McCullough, 2007; Targher et al., 2006).

\subsection{Diagnostic criteria}

Clinically, most patients with NAFLD exhibit no liver symptoms. The disease is often suspected merely on grounds of (mildly) raised transaminase levels and/or gammaglutamyltranspeptidase (GGT). An ASAT/ALAT ratio of $>1$ points to an alcoholic aetiology. Patients with NASH often suffer from illnesses that go hand in hand with insulin resistance. However, the presence of a metabolic syndrome does not exclude alcoholic hepatopathy (Dufour \& Oneta, 2004).

In clinical practice, there is so far no means of differentiating reliably between simple steatosis and steatohepatitis solely on the basis of non-invasive (e.g. laboratory chemical) diagnostic tests (American Gastroenterological Association [AGA], 2002; Bellentani et al., 2004; Farrell \& Larter, 2006). Histological demonstration of persistent liver cell damage is 
believed to be the best current marker for evaluation of disease progression (Gramlich et al., 2004). The question of whether transaminase levels correlate with the histological findings has still not been answered definitively (Sonsuz et al., 2000), particularly with respect to necroinflammatory activity and the degree of fibrosis. Determination of the hepatic apoptotic activity in serum (activated caspase 3, keratin 18-fragment analysis) possibly has clinical value as a non-invasive diagnostic criterion for NASH (Wieckowska et al., 2006). Furthermore, isolated reports of non-invasive scoring systems for fibrosis have been published, but their potential diagnostic and/or prognostic role in clinical practice remains unclear (Angulo et al., 2007; Farrell \& Larter, 2006).

The morphological sign of non-alcoholic steatosis is a predominantly macrovesicular accumulation of lipids usually beginning at a perivenular site in the centre of a lobe. The lower limit has been set at fatty degeneration of $5 \%$ of the surface of the liver parenchyma (Kleiner et al., 2005; Neuschwander-Tetri \& Caldwell, 2003). However, this does not seem to be adequately justified (Brunt \& Tiniakos, 2005; Cortez-Pinto et al., 2006). Mild steatosis affects $<33 \%$ of the parenchymal surface, moderate steatosis involves $33-66 \%$, and severe steatosis covers $>66 \%$ (Brunt, 2001, 2002, 2005a, 2005b; Brunt et al., 2003, 2004; Brunt \& Tiniakos, 2002, 2005; Burt et al., 1998). The steatosis (of variable degree) is accompanied by usually slight mixed-cell inflammatory infiltrates (neutrophilic, granulocytic and lymphocytic cells) in the hepatic lobes. A further morphological criterion is cell ballooning, i.e. liver cell damage in the form of swelling. This can usually been seen in the vicinity of fatladen hepatocytes and thus also typically in the centre of a lobe. Other typical, albeit not diagnostically decisive parameters are lipogranulomas and periportal glycogen containing nuclei. Mallory-Denk bodies (MDB), usually can be demonstrated in the swollen cells. The fibrosis also starts in the centre of the affected lobe, in perivenular and perisinusoidal locations. Sometimes pericellular fibrosis can be detected. As the disease progresses, portal fibrosis with formation of portoportal and portocentral bridging septa arises. No single one of these structures should be used as a so-called 'minimal criterion' without the simultaneous demonstration of ballooning (Brunt, 2001, 2002, 2005a, 2005b; Brunt et al., 2003, 2004; Brunt \& Tiniakos, 2002, 2005; Burt et al., 1998 Neuschwander-Tetri \& Caldwell, 2003).

The Cleveland group suggested classification of NAFLD (on prognostic grounds) into the following types:

Type 1 , simple steatosis

Type 2, steatosis and inflammation

Type 3, steatosis and cell swelling (ballooning)

Type 4, steatosis, cell swelling (ballooning), and MDB or fibrosis

Progression to cirrhosis is found predominantly in types 3 and 4, both of which correspond to the typical histopathological picture of NASH (Brunt, 2001, 2002, 2005a; Brunt et al., 2003, 2004; Brunt \& Tiniakos, 2002, 2005; Neuschwander-Tetri \& Caldwell, 2003 Falck-Ytter et al., 2001; Matteoni et al., 1999). For morphological manifestations of paediatric NASH (see 5.3).

\section{Indication for biopsy}

While scientists have been searching for non invasive diagnostic procedures for confirming diagnosis and determining inflammatory activity and potential fibrosis of fatty liver disease, to date histological evaluation remains the sole method of distinguishing steatosis from advanced forms of NAFLD. 
Thus, liver biopsy is the gold standard for confirmation of the diagnosis and for determination of the inflammatory activity and possible presence of fibrosis in fatty liver disease. In deciding whether biopsy is indicated, one should weigh the potential information gain and its consequences against the resources invested and the complication rate, i.e. consider the clinical context. No blanket recommendation for liver biopsy in either suspected or confirmed fatty liver disease can currently be given.

The indication for biopsy in assumed fatty liver disease depends on the clinical context. Decisive is the likelihood that the biopsy findings will have consequences for the patient's behaviour or for therapy. These possible consequences include:

Confirmation of fatty liver disease, in particular steatohepatitis, and its treatability; exclusion of steatohepatitis as cause of unexplained elevation of transaminases; exclusion or confirmation of comorbidities; ascertainment of status quo, $935,41,44$

Deciding the appropriate treatment approach (e.g. bariatric surgery, suitability for transplantation; treatment of any comorbidity)

Motivation for behavioural modification or ascertainment of its effect (e.g. weight reduction, physical activity)

Participation in clinical studies or protocol biopsies

Special indications (e.g. assessment of explanted livers)

In this context liver biopsy must clarify the following points:

Confirmation of possible or assumed fatty liver; clarification of steatohepatitis; confirmation or exclusion of liver disease other than fatty liver disease (typing)

Extent of inflammatory activity (grading)

Degree of fibrosis and any destruction of hepatic architecture (staging)

Liver biopsy is the current "gold standard" for analysis of these issues and cannot be replaced by any non-invasive procedure (Adams \& Talwalkar, 2006; Angulo \& Lindor, 2002; Brunt et al., 2004; Joy et al., 2003; Neuschwander-Tetri, 2002; Wieckowska et al., 2007). It is advisable to discuss the implications of liver biopsy with the patient during the course of diagnostic clarification of possible or probable fatty liver disease. While a pronounced case of fatty liver can be diagnosed with some certainty from the findings of clinical examination and imaging procedures, particularly the extent of the fatty degeneration and the presence or absence of the many possible accompanying liver diseases cannot be determined with any certainty by non-invasive means. There are no serological tests for diagnosis or quantification of fatty degeneration of the liver parenchyma. Comparative investigations have shown that elevation of serum transaminase concentrations can point to impairment of the hepatic parenchyma, but an absence of serum transaminase elevation in fatty liver disease does not exclude inflammatory activity in liver tissue (Mofrad et al., 2003). While in principle fatty liver disease is thought to be swiftly reversible and unlikely to progress, steatohepatitis entails a significant risk of progression to severe fibrosis or cirrhosis, so that the determination of inflammatory activity has considerable prognostic relevance Matteoni et al., 1999; Teli et al., 1995; Harrison ez al., 2003; Adams \& Talwalkar, 2006; Wieckowska et al., 2007).

Numerous non-invasive procedures for diagnosis of liver fibrosis have been and are being developed. Serological tests are based on algorithms, some of which are independent of fibrosis while others integrate parameters associated with hepatic fibrogenesis (Younossi et al. 2008). Currently these tests can support the diagnosis of advanced liver fibrosis, but alone, particularly in the presence of only slight to moderate changes, they can neither confirm nor exclude fibrosis with sufficient certainty; therefore, they are unsuitable for 
staging. Elastography is a method for determining the stiffness of the liver, which correlates with extent of fibrosis, at least during follow up. Particularly the presence or absence of severe fibrosis/cirrhosis can be assessed with high accuracy (Castera et al., 2008). The advantages of this method are its repeatability, its low inter- and intra-observer variability and its lack of side effects; its disadvantages are inadequate detection of slight and moderate fibrosis, lack of grading ability, significant interference by other liver changes (fatty degeneration, inflammatory activity, cholestasis, congestion) and by extrahepatic factors (morbid obesity, ascites) (Friedrich-Rust et al., 2008). For these reasons the diagnostic potential of elastography in fatty liver disease has been evaluated in only a few studies to date, so the method has not yet been adequately validated. In particular its role in the monitoring of the course of fatty liver disease should be further investigated. None of the tests mentioned above is suitable for assessment of destruction of hepatic architecture. Other procedures, e.g. magnetic resonance elastography for measurement of fibrosis (Bonekamp et al., 2009), are currently inadequately validated or not validated at all, and therefore cannot be recommended.

Although liver biopsy is superior to all other investigations with regard to number of relevant parameters assessed and predictive power, it cannot always be recommended as diagnostic method in possible or sufficiently confirmed fatty liver disease. Several factors affect the decision whether or not to perform biopsy:

Because biopsy is an invasive technique, the information it can be expected to yield must be balanced against the resources invested and the - albeit low - complication rate. The rate of fatal complications of liver biopsy is generally reported as $0.01 \%$. Major intervention- or hospitalisation-related complications such as intraperitoneal haemorrhage occur in about $0.3 \%$ of cases, while more minor complications, e.g. transient pain, are observed in $20-30 \%$ of patients (Strassburg \& Manns, 2006).

The issue of clinical consequences: The current treatment options for fatty liver disease are limited. Biopsy sampling of liver tissue for examination may be particularly useful, however, before invasive treatment measures such as bariatric surgery or liver transplantation (Tannapfel \& Reinacher-Schick, 2008). In the medium term novel treatments, including medicinal approaches can be expected, entailing reassessment of the value and necessity of liver biopsy. To what extent knowledge of the findings of liver biopsy influences the patient's behaviour (weight reduction, physical activity) has to be considered on an individual basis.

Donor livers with $<30 \%$ fatty degeneration can be transplanted with no danger of primary transplant failure (Nocito et al., 2006).

\section{Harvesting and processing of biopsy material / histomorphological evaluation / scoring system}

The structural diagnostic criteria for NAFLD may be unevenly distributed in the liver. Thus, histological diagnosis on the basis of biopsy samples may be associated with possibly considerable sampling error (Ratziu et al., 2005). This may affect both, the diagnostic differentiation between steatosis and steatohepatitis and estimation of the extent of fibrosis (staging).

Harvesting and processing of the biopsy cylinder should observe the standard recommendations for liver biopsy. The cylinder should contain representative tissues, be about $25 \mathrm{~mm}$ long and or contain 15 portal fields (Rousselet et al., 2005). Fixation and 
processing are routine (4\% neutral buffered formalin, embedding in paraffin with the usual dehydration and preparation of routine stains such as haematoxylin and eosin, Berlin blue for demonstration of iron, PAS-diastase stain and reticulin and connective tissue staining). Sirius red staining is recommended for morphometric assessment. Immunohistological staining is not routinely required. An immunohistochemical reaction with antibodies to keratin 7 or 19 can be carried out to facilitate demonstration of gall duct lesions. Sensitive depiction of any MDB that may be present can be achieved with ubiquitin antibodies. With regard to ballooning of hepatocytes, which is included in the scoring system, demonstration of the intermediate filament cytoskeleton with antibodies against keratin 8 or 18 may be helpful, as this cytoskeletal system is reduced in cell ballooning (Lackner et al., 2008). The staging of fibrosis is shown in Table1.

The following histological criteria should be considered when interpreting and diagnosing non-alcoholic steatohepatitis: micro- or macrovesicular fatty degeneration, fibrosis, lobular inflammation - typically comprising polymorphonuclear granulocytes, lymphocytes and activated Kupffer cells - lipogranulomas, hepatocyte ballooning, acidophilic bodies, ceroidcontaining macrophages and megamitochondria. Additional changes are MDB and glycogen-contaning nuclei.

\begin{tabular}{|c|c|}
\hline Stage & Histological findings \\
\hline 0 & No fibrosis \\
\hline a & Zone 3, perisinusoidal fibrosis, special staining (i.e. EvG) required \\
\hline 1b & Zone 3, perisinusoidal fibrosis, can be detected with H\&E \\
\hline 1c & Only periportal/portal fibrosis \\
\hline 2 & Zone 3, plus portal/periportal fibrosis \\
\hline 3 & As above, but with bridging fibrosis \\
\hline 4 & Cirrhosis \\
\hline
\end{tabular}

Table 1. Degree of fibrosis (staging)

Steatosis, inflammatory changes and hepatocytic injury can be semiquantified as a 'Brunt Score' (Brunt et al., 1999) (Table 2) or 'NAS' (NAFLD activity score; Table 3), providing the basis on which to decide whether or not steatohepatitis is present.

\begin{tabular}{|c|c|c|c|}
\hline Activity & Steatosis & Ballooning & Inflammation \\
\hline Mild: grade 1 & $1-2$ (up to $66 \%)$ & Minimal & $\begin{array}{c}\text { Lobular: } 1-2 \\
\text { Portal: none to mild }\end{array}$ \\
\hline $\begin{array}{c}\text { Moderate: grade } \\
2\end{array}$ & $\begin{array}{c}2-3(>33 \%, \\
\text { occasionally }>66 \%)\end{array}$ & Clear & $\begin{array}{c}\text { Lobular: } 2 \\
\text { Portal: mild to } \\
\text { moderate }\end{array}$ \\
\hline Severe: grade 3 & $3(\geq 66 \%)$ & Marked & $\begin{array}{c}\text { Lobular: } 3 \\
\text { Portal: mild to } \\
\text { moderate }\end{array}$ \\
\hline
\end{tabular}

Table 2. NASH activity grading. Steatosis grade $1: \leq 33 \%$; grade $2:>33 \%,<66 \%$; grade $3: \geq$ $66 \%$

The NAS (NAFLD activity score) is a refinement of the Brunt score, derived by separate semiquantification of each of the three components - steatosis, hepatocyte ballooning and lobular inflammation - and addition to form a total score. 


\begin{tabular}{|c|c|c|c|}
\hline NAS & $\begin{array}{c}\text { Steatosis (\% fat } \\
\text { deposition in } \\
\text { hepatocytes) }\end{array}$ & $\begin{array}{c}\text { Ballooning } \\
\text { hepatocytes }\end{array}$ & $\begin{array}{c}\text { Lobular } \\
\text { inflammation }\end{array}$ \\
\hline 0 & $<5 \%(0)$ & None (0) & None (0) \\
\hline 3 & $5-33 \%(1)$ & Few (1) & $\begin{array}{c}1-2 \text { foci per 200x } \\
\text { field (1) }\end{array}$ \\
\hline 6 & $34-66 \%(2)$ & Many (2) & $\begin{array}{c}2-4 \text { foci per 200x } \\
\text { field (2) }\end{array}$ \\
\hline 8 & $>66 \%(3)$ & Many (2) & $\begin{array}{c}>4 \text { foci per 200x field } \\
(3)\end{array}$ \\
\hline
\end{tabular}

Table 3. NAFLD activity score (grading): The numbers in parentheses give the NAS for each histological criterion

Evaluation and semiquantitative analysis for grading (Brunt et al., 1999):

Grade of fatty degeneration:

$\begin{array}{ll}<5 \% & =\text { grade } 0 \\ 5-33 \% & =\text { grade } 1 \\ 34-66 \% & =\text { grade } 2 \\ \text { More than } 66 \% & =\text { grade } 3\end{array}$

Grade of lobular inflammation:

Absent

Up to 2 foci per field of view (200× magnification)

$=$ grade 0

2 to 4 foci per field of view

$=$ grade 1

$=$ grade 2

More than 4 foci per field of view

$=$ grade 3

Lipogranulomas are included in the category of inflammation

Ballooning:

Absent

Few ballooned hepatocytes

Many ballooned hepatocytes

$$
\begin{aligned}
& =\text { grade } 0 \\
& =\text { grade } 1 \\
& =\text { grade } 2
\end{aligned}
$$

This scoring system is readily reproducible and can provide the basis for deciding whether steatohepatitis should be diagnosed or not:

$0-2$

$3-4$ definitely no steatohepatitis

5 or more questionable

The scoring can also be applied to paediatric cases (Brunt EM, 2007; Schwimmer et al., 2005). The staging according to grade of fibrosis (Table 2b, after Kleiner et al., 2005) should also be evaluated:

Stage 1 is divided into $1 \mathrm{a}$ with slight central fibrosis and $1 \mathrm{~b}$ with dense perisinusoidal fibrosis accompanied by central vein sclerosis and adjacent perisinusoidal fibrous extension. Stage 1c is used only for portal fibrosis, which may certainly occur at an early stage. Stage 2 is portal and central fibrosis. In analogy with the staging of chronic hepatitis, stage 3 is bridging fibrosis and stage 4 corresponds to cirrhosis.

The presence of MDB should also be recorded (Mendler et al., 2005). 
The proposed scoring systems have not yet been generally accepted. Numerical scores alone should not replace histological diagnosis.

In Figures 1 - 4 typical images of different histopathological conditions for both, grade of steatosis and grade of fibrosis are presented.

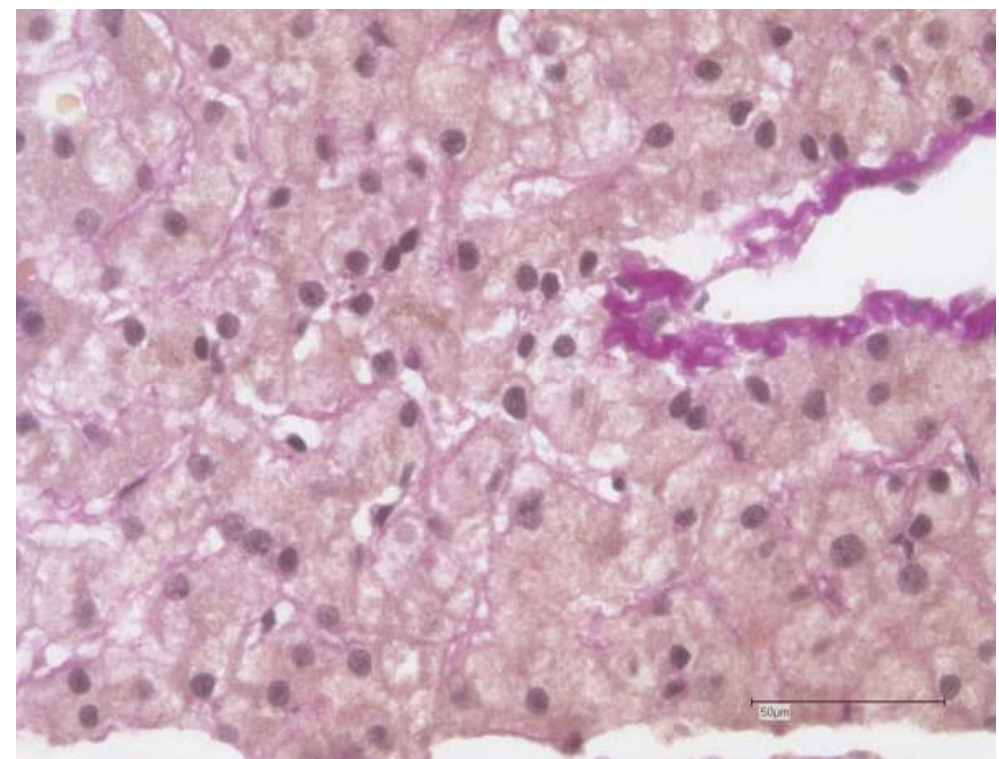

Fig. 1. Non-alcoholic steatohepatitis: fat $10 \%$, score: 1 plus 1 plus $1=3$, fibrosis grade $1 \mathrm{~B}$

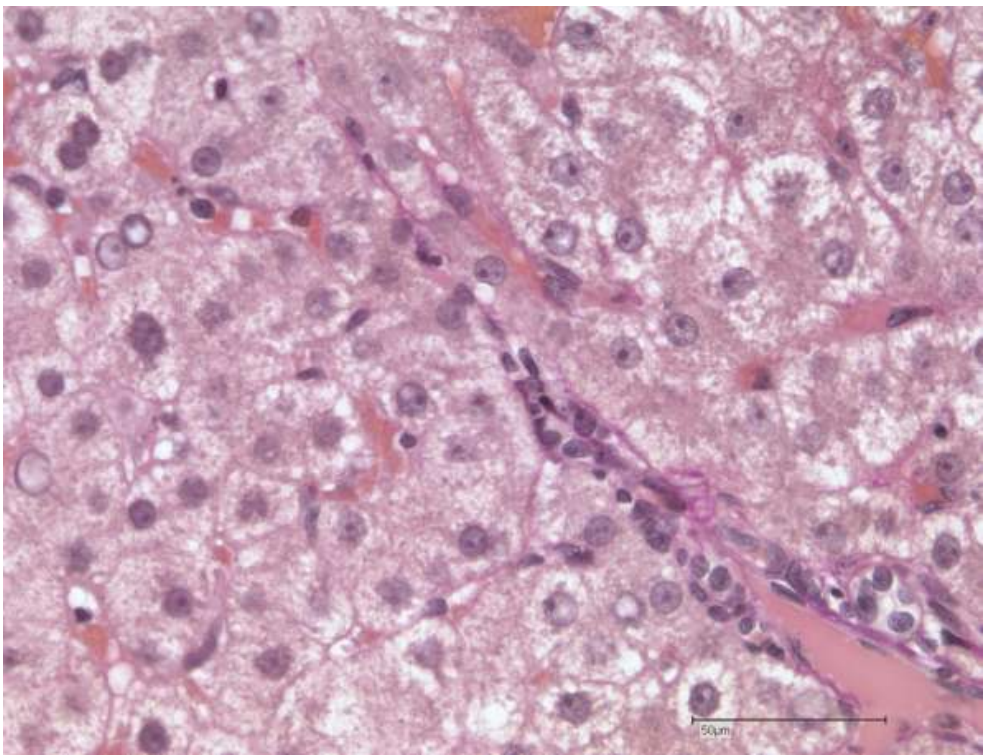

Fig. 2. Non-alcoholic steatohepatitis: fat $8 \%$, score 1 plus 1 plus $1=3$, fibrosis grade $1 \mathrm{c}$ 


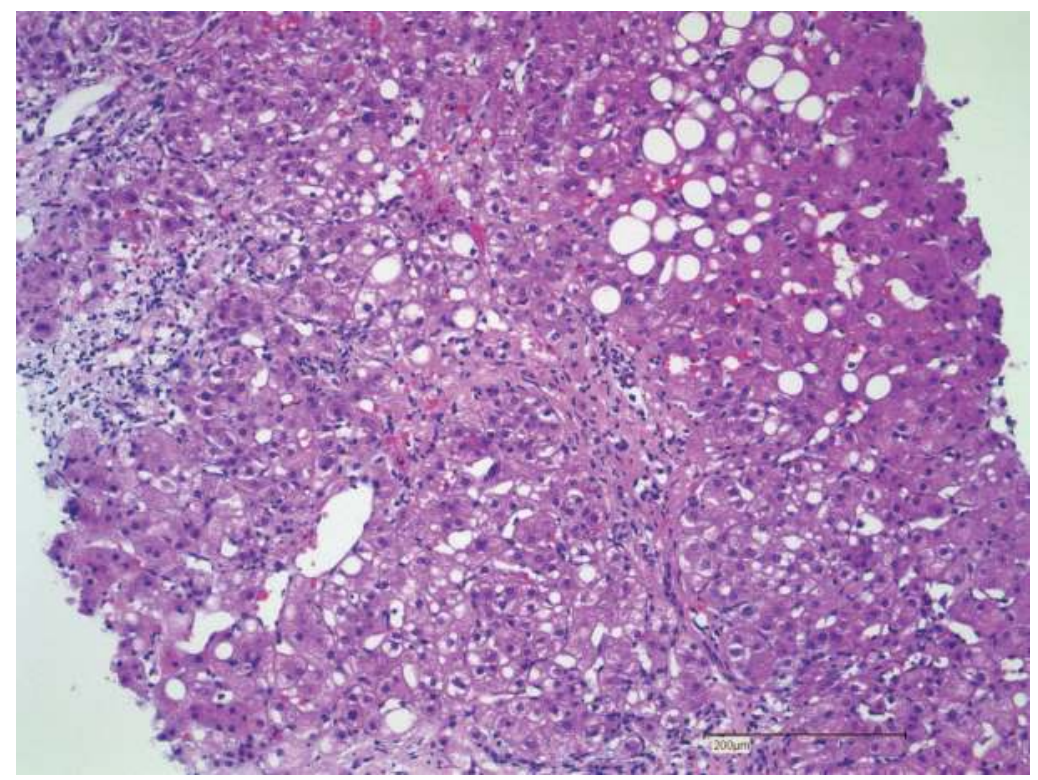

Fig. 3. Non-alcoholic steatohepatitis: fat $30 \%$, score 1 plus 1 plus $1=3$, fibrosis grade 3

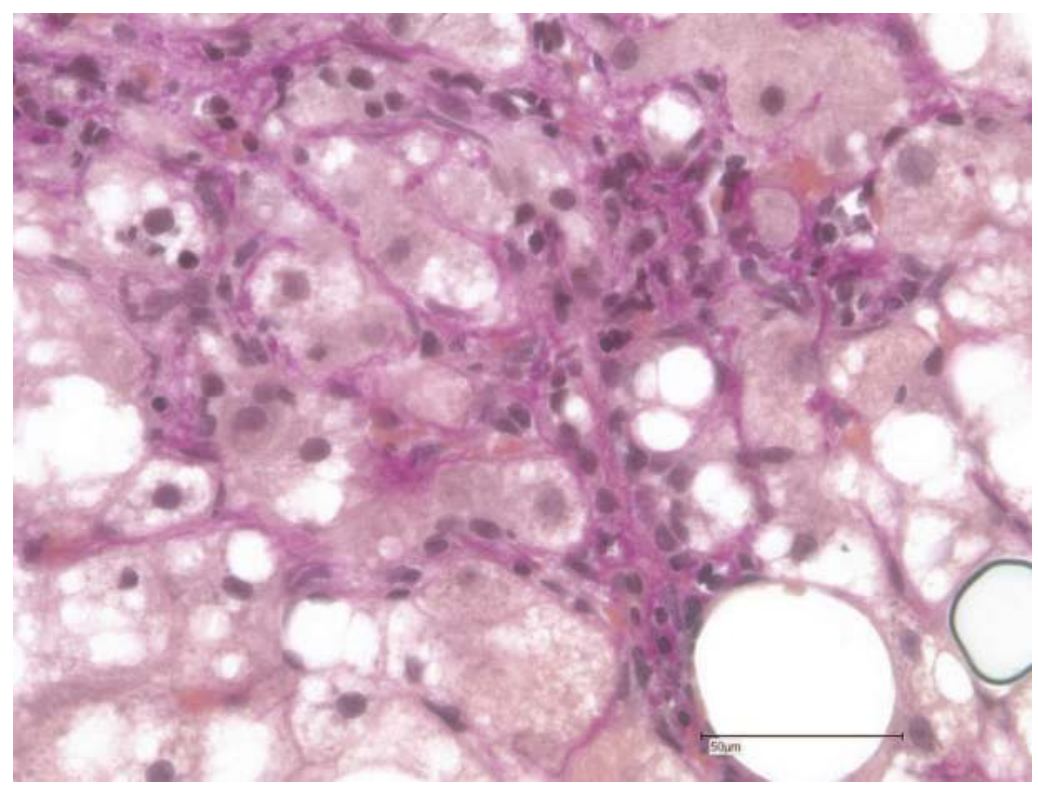

Fig. 4. Non-alcoholic steatohepatitis with cirrhosis: fat $40 \%$, score: 2 plus 2 plus $1=5$, fibrosis grade 4 


\section{Diagnosis and differential diagnosis}

It is important to differentiate between ASH and NASH and also to differentiate both of them from viral hepatitides and chemotoxicity-related steatohepatitides. The histopathological peculiarities of fatty liver diseases in the paediatric age group must also be borne in mind.

The criteria used for the morphological definition of steatohepatitis are fatty degeneration of liver cells (steatosis), predominant in zone 3, lobular and/or portal field-dominant inflammatory reaction (inflammation), direct liver cell damage in the form of ballooned hepatocytes, possibly Mallory-Denk bodies (MDB), fibrosis and possibly accumulation of iron.

- Steatosis

Fatty degeneration of liver cells is documented in virtually all existing studies on ASH and $\mathrm{NASH}^{4}$.

Macrovesicular steatosis results from the discrepancy between synthesis of lipids and their export from the hepatocytes.

Microvesicular steatosis, a possible precursor of macrovesicular steatosis, is thought to be a consequence of severe hepatocytic damage as a result of defective $\beta$-oxidation of fatty acids. The toxic effects of some medicinal drugs can also lead to microvesicular steatosis. In the course of ASH or NASH there may be complete loss of fat; thus, for example, cryptogenic cirrhosis with only slight fatty degeneration of liver cells is not infrequently ascribable to NASH (Caldwell et al., 1999; Oneta \& Dufour, 2003).

- Lobular and/or portal inflammation and hepatocyte ballooning

ASH and NASH are characterised by a lobular inflammatory cell infiltrate with a variable number of leucocytes. Not infrequently the inflammatory cells are found to enclose ballooned hepatocytes. So-called lipogranulomas, i.e. inflammatory cells (including Kupffer cells and eosinophilic granulocytes) enclosing a fat-laden hepatocyte, may be seen but are not considered pathognomonic for NASH or ASH (Caldwell et al., 1999; Reid, 2001). The direct hepatocyte damage is shown by the aforementioned ballooning, which may progress to necrosis or apoptosis. Hepatocytes of zone 3 are affected most frequently (Brunt, 2005; Brunt \& Tiniakos, 2005; Burt et al., 1998; Neuschwander-Tetri \& Caldwell , 2003). MDB do not contribute to differentiation between ASH and NASH.

- Fibrosis

The characteristic fibrosis pattern in ASH and NASH is pericellular fibrogenesis. Collagen is found in the Disse spaces. In both ASH and NASH, zone 3 is affected first, with periportal fibrosis not infrequently observed in the liver of patients with diabetes mellitus type 1 (NASH patients). It seems that portal field fibrosis tends to predominate in ASH. Taken alone, however, this pattern of fibrosis is not a criterion for differentiation between ASH and NASH.

5.1 Differential diagnosis of alcoholic (ASH) and non-alcoholic steatohepatitis (NASH) In general, histological criteria alone do not permit confident differentiation between ASH and NASH (Oneta \& Dufour, 2003). Nevertheless, some findings may be helpful in differential diagnosis (Brunt, 2002; Brunt, 2007), although to date there is no published evidence:

- Fat

Microvesicular steatosis and "foamy" degeneration of the liver seem to indicate incipient hepatic decompensation in patients with ASH and are less common in NASH. 
Patients with NASH usually exhibit more advanced fatty degeneration of liver cells than those with ASH. The affected hepatocytes, concentrated at periportal sites, more frequently display intranuclear vacuoles.

In addition to the nuclear vacuoles, patients with diabetes mellitus show fibrosis usually starting in zone 1, where MDB may also be found. Patients with NAFL who display pronounced weight increase or a jejunoileal bypass tend to exhibit portal inflammation with only slight portal fibrosis.

Only in decompensated ASH may any appreciable cholestasis occur, usually intracanalicular and sometimes with a secondary phenomenon such as pancreatitis or haemolysis as a contributory cause.

- Inflammation

As a general rule, the inflammatory infiltrate in NASH is somewhat less pronounced than in ASH. MDB are more frequent and more distinctive in ASH than they are in NASH. So-called satellitosis, granulocytic demarcation of a hepatocyte with MDB, is more frequent in ASH than in NASH.

- Fibrosis

Indicative, though not specific, for ASH are the so-called sclerosing hyaline necroses, usually in combination with obliterating vascular lesions. The latter are also considered to be responsible for the non-cirrhotic 00portal hypertension in patients with ASH. Sclerosing hyaline necroses are thought to represent a combination of liver cell necrosis and loss (predominantly in zone 3) and dense perivenular and perisinusoidal fibrosis to the point of venous obliteration (with or without MDB).

\begin{tabular}{|c|c|c|}
\hline Finding & ASH & NASH \\
\hline Steatosis & + & ++ \\
\hline Ballooning & ++ & ++ \\
\hline Lobular inflammation & ++ & $+/++$ \\
\hline Portal granulocytic inflammation & ++ & $--/+$ \\
\hline Mallory-Denk bodies (MDB & +++ & + \\
\hline Satellitosis & +++ & -- \\
\hline Acute cholestasis & + & + \\
\hline Perisinusoidal fibrosis & + & -- \\
\hline Sclerosing hyaline necrosis & ++ & -- \\
\hline Veno-occlusive disease (VOD) & ++ & \\
\hline
\end{tabular}

Table 4. Criteria for differentiation of ASH and NASH

Venous or perivenular fibrosis, phlebosclerosis and (less commonly) lymphocytic phlebitis occur more frequently in ASH than in NASH. Phlebosclerosis is a frequent sign of alcoholassociated cirrhosis of the liver.

Cholestasis is found in around a third of all livers with ASH, less often in patients with NASH. Ductular proliferates are encountered more frequently in ASH than in NASH.

Criteria for differentiation of ASH and NASH see table 4.

\subsection{Differential diagnosis of ASH, NASH / hepatitis / drug-induced hepatitis}

The criteria for differentiation of NASH or ASH from hepatitis C virus infection are firstly the characteristic portal inflammatory infiltration pattern of $\mathrm{HCV}$ infection, and secondly 
the lack of typical hepatocyte ballooning and the intra-acinar granulocytic inflammation (Sanyal et al., 2006).

Differentiation among ASH / NASH, hepatitis C virus infection and liver damage by toxic effects of medications ('drug-induced hepatitis') is possible. In patients exhibiting signs of more than one of these diseases, discussion embracing the clinical parameters is necessary to identify the essential contributory factors.

Chronic HCV infection can also lead to macrovesicular steatosis. In particular, patients infected with HCV genotype 3 usually show more advanced fatty degeneration. However, the hepatocyte ballooning and intralobular granulocytic inflammation typical of ASH and NASH are absent.

Drug-induced hepatitis is characterised by portal and particularly intra-acinar inflammation that consists principally of neutrophilic and eosinophilic granulocytes. Cholestasis is found, and in severe cases liver cell necrosis. Steatosis does not necessarily occur in drug-induced hepatitis (exceptions include tamoxifen and amiodarone), but is often found in patients who evince certain risk factors (high BMI, diabetes mellitus). Selected drugs that may lead to steatosis are e.g Acetylsalicylic acid, Amiodarone, Didanosine (stavudine), MDMA (amphetamines).

\subsection{Special form: paediatric fatty liver disease}

As applies for adults both NAFLD and NASH can occur without any apparent risk factor even in children. The sole clinical manifestation is usually a persistent slight (one- to twofold) elevation in transaminases. In about $80 \%$ of the affected children and adolescents the NAFL is discovered incidentally in overweight or obese individuals. The remainder display normal weight but the majority are diabetics.

Paediatric NASH exhibits histological differences from adult NASH. The question of liver biopsy is controversial; nevertheless, there is consensus that, particularly in the event of repeated elevation of liver enzymes, chronic liver diseases such as hepatitis B and C, Wilson's disease and autoimmune hepatitides should first be ruled out. Weight reduction should be attempted. In patients who lose a moderate amount of weight over a period of six months but do not achieve normalisation of liver function, liver biopsy should be performed for definitive confirmation of the diagnosis and assessment of the prognosis. If at any time during this period evidence emerges of another disease or a competing or concurrent liver ailment (demonstration of autoantibodies, caeruloplasmin decrease), diagnosis should not be postponed until after weight reduction but ascertained immediately, with liver biopsy if necessary.

For assignment of the diagnosis of NAFLD in childhood or adolescence, fat has to make up at least $5-10 \%$ of the liver by weight. In analogy to the classification of fatty liver disease in adults, the steatosis is categorised as mild (less than a third of hepatocytes affected), moderate (up to two thirds of hepatocytes affected) or severe (more than two-thirds of hepatocytes affected) (Hubscher, 2004). Among adults with NAFLD, 1 - 3\% go on to develop cirrhosis of the liver. If this is true for the paediatric age group, many children are at increased risk of early progressive liver fibrosis or cirrhosis.

Differences between paediatric and adult NAFLD:

To date there have been no studies on the prognosis of NAFLD. It also remains unclear what influence puberty and growth have on the time course of the disease. Adult NASH patients have a $25 \%$ risk of developing advanced liver fibrosis within 5 years and a $15 \%$ risk of cirrhosis in the same period (Neuschwander-Tetri \& Caldwell, 2003). The significance of 
ethnicity is hotly debated. Children of Hispanic and Asiatic origin are at greater risk. In contrast to the situation in adults with non-alcoholic liver disease, males are predominantly affected in the paediatric age group (DeLeve et al., 2002; Roberts, 2007).

The first study on the histopathology of paediatric NAFLD and hepatitis found that they largely resemble the picture in adult disease, but display differing morphological aspects. With regard to inflammation and fibrosis, two subtypes can be distinguished (Schwimmer et al., 2005). In general the livers of children and adolescents with NASH reveal less lobular and more portal inflammation, and the fibrosis tends to be more portal rather than perisinusoidal (Rashid \& Roberts, 2000; Roberts, 2007; Papandreou et al., 2007). This distinctive histological feature could explain the early progression of the NAFLD score in children and adolescents compared with adults. Biopsy samples exhibit more marked fatty degeneration than in adult NASH. The characteristic ballooning of hepatocytes in adults is also absent, as is the pronounced lobular inflammation with perisinusoidal fibrosis. Only in $12 \%$ of cases is paediatric NAFLD histologically comparable to the adult disease (Schwimmer et al., 2005; Schwimmer, 2007). The differential diagnoses include Wilson's disease, other disorders of hepatic metabolism (including rare diseases) and chronic inflammatory bowel diseases, which may manifest as diarrhoea with weight loss. Differentiation from hepatitis is particularly important.

\subsection{Special form: chemotherapy-associated steatohepatitis (CASH)}

Persons at increased risk of developing fatty liver are in greater danger of developing chemotherapy-associated steatohepatitis (CASH). Close monitoring of liver function before hepatic resection is recommended in these patients. Possible causes of elevation of liver enzymes before initiation of chemotherapy include malignant involvement of the liver and other chronic hepatic diseases as well as fatty liver disease. Liver biopsy may be necessary for differential diagnosis.

Severe liver changes have been observed following chemotherapy administered in the context of liver resection, particularly extirpation of colorectal metastases. These adverse effects of chemotherapy on the liver tissue around a tumour can lead to postoperative impairment of liver function.

The described changes resemble the histological findings after conditioning chemotherapy and subsequent allogenic stem cell transplantation in the liver. The liver damage after chemotherapy depends decisively on the degree of previous liver impairment. Neoadjuvant chemotherapy may be followed not only by sinusoidal obstruction syndrome (SOS) (DeLeve et al., 2002), but also by slight steatosis, steatohepatitis or even combined steatohepatitis and SOS (Karoui et al., 2006) . In principal, any of the cell populations in the liver can be affected by drug-induced damage. Cholangiocytes are considered to be relatively inert. Hepatocytes, followed by vascular endothelia, are the primary cell systems in which damage may also be visible on light microscopy. The changes may extend as far as fibrosis, accompanied by vascular wall damage and parenchymal bleeding.

- Fatty degeneration of liver cells

Fatty degeneration after chemotherapy with 5-fluorouracil (5-FU) is generally considered to be reversible after discontinuation of the treatment. Particularly in the case of pre-existing fatty liver, however, the rate of complications after liver resection is higher. Chemotherapyinduced fatty degeneration of liver cells can lead to functional impairment after liver resection. 
- Steatohepatitis (fatty liver hepatitis)

It is known that, for example, 5-FU, taxanes or platinum-containing chemotherapeutics exert oxidative stress not only on tumour cells but also on non-neoplastic parenchymal and stromal cells (Tannapfel et al., 2001). This prompted the proposal to adopt the term "chemotherapy-associated steatohepatitis" (CASH) (Gentilucci et al., 2006; Zivkovic et al., 2007).

The metabolic pathway of some drugs is known in detail. Thus the topoisomerase-I inhibitor irinotecan (CPT11) is thought to trigger CASH even in a previously intact liver. The damage is assumed to be predominantly hepatocytic because of the glucuronidation of hepatocytes. Sublethal liver damage may be manifested by hepatocyte ballooning, microvesicular steatosis and finally inflammation with subsequent fibrosis. Like ballooning, hepatocellular cholestasis is considered to be a sign of direct cell damage. In the treatment of colorectal carcinoma irinotecan is almost always used in combination with 5-FU, so the hepatotoxic effects may be additive.

- Vascular endothelial damage

The endothelial cells can also be damaged by oxidative stress. Histologically, the vessels are occluded by connective tissue (Aloia et al., 2006; Vauthey et al., 2006; Zivkovic et al., 2007), with coexisting inflammation, fibrosis and embolic occlusion of small and larger downstream vessels. Damage of these cells in the terminal hepatic venules and sublobular veins causes on the one hand activation of the coagulation cascade (thrombosis) and on the other, hyperfibrinolysis (bleeding). These disseminated intravasal coagulations in the liver result in inflammation and subsequent fibrosis to the point of vascular occlusion. Macroscopically, the affected liver is rich in blood, spongy and livid ("blue liver"); its elasticity is diminished.

Here too the effects of various substances may be additive.

Platinum-containing chemotherapeutics (particularly oxaliplatin) also possess high hepatotoxic potential (endothelial damage, sinusoidal lesions, SOS). Resected liver tissue from patients treated with a combination of 5-FU and oxaliplatin reveal, besides sinusoidal lesions with bleeding, vascular thrombosis and vascular fibrosis, signs of CASH, with hepatocytic necrosis, fatty degeneration of liver cells and cholestasis. These changes may be visible as early as 20 days after inception of therapy.

The histological changes after administration of site-specific treatments, e.g. monoclonal antibodies against the EGF receptor or VEGF, have not yet been the subject of controlled studies.

- Classification system for staging

The precise relationship between fatty degeneration of liver cells and SOS has not yet been clearly defined. A further open question is the dose-effect relationship. Moreover, it remains unclear whether the histological changes are reversible. There seems to be no linear correlation between liver damage and elevated liver enzymes in peripheral blood. To date there is neither a clinical nor a histological classification or graduation system that would allow "staging" of the change, much less prediction of the outcome. Therefore, it can merely be recommended that liver function be closely monitored before liver resection in patients at risk of developing fatty liver (e.g. high BMI, metabolic syndrome, diabetes mellitus) (Aloia et al., 2006; Nakano et al., 2008). If the liver enzymes are elevated before initiation of chemotherapy and the cause is not tumour involvement, a full battery of laboratory tests may need to be accompanied by liver biopsy to establish the exact extent of fatty degeneration, ballooning or fibrosis. In particular, special attention should be paid to 
histological processing of the tissue surrounding the metastasis in specimens resected from patients who have undergone chemotherapy.

\section{Genetic prevalence}

At the moment, the question of genetic prevalence of NAFLD and NASH is under investigation and is obviously higher than estimated previously (Williams et al., 2011). Recently several genetic factors such as patatin-like phospholipase 3 or apolipoprotein C3 have been characterized in NAFLD (Valenti et al., 2010; Petersen et al., 2010). Even genomewide association studies (GWASs) of liver histology in patients with non alcoholic fatty liver disease have been performed to estimate genetic susceptibility to NASH (Chalasani et al., 2010). However, these findings have to be validated.

\section{Conclusion}

Diagnostic procedures in patients with suspected fatty liver disease should be standardized and generally accepted. The publications on predisposition to ASH or NASH, however, cannot be uniformly interpreted because of ethnic or physiological differences among the populations analysed. It is therefore important to evaluate the situation objectively and work towards reasonable diagnostic procedures that serve the needs of these patients.

\section{References}

Adams, L. A. \& Talwalkar, J. A. (2006). Diagnostic evaluation of nonalcoholic fatty liver disease. J.Clin.Gastroenterol., Vol. 40, No. 3 Suppl 1, (March 2006), p. S34-S38, ISSN 0192-0790

AGA (2002), American Gastroenterological Association medical position statement: nonalcoholic fatty liver disease. Gastroenterology, Vol. 123, No. 5, (November 2002). pp. 1702-1704, ISSN 7645-6

Alfire, M. E. \& Treem, W. R. (2006). Nonalcoholic fatty liver disease. Pediatr.Ann., Vol. 35, No. 4, (April 2006), pp. 290-299, ISSN 0090-4481

Aloia, T., Sebagh, M., Plasse, M., Karam, V., Levi, F., Giacchetti, S., Azoulay, D., Bismuth, H., Castaing, D., \& Adam, R. (2006). Liver histology and surgical outcomes after preoperative chemotherapy with fluorouracil plus oxaliplatin in colorectal cancer liver metastases. J.Clin.Oncol., Vol. 24, No. 31, (1 November 2006), pp. 4983-4990, ISSN 0732-183X

Angulo, P., Hui, J. M., Marchesini, G., Bugianesi, E., George, J., Farrell, G. C., Enders, F., Saksena, S., Burt, A. D., Bida, J. P., Lindor, K., Sanderson, S. O., Lenzi, M., Adams, L. A., Kench, J., Therneau, T. M., \& Day, C. P. (2007). The NAFLD fibrosis score: a noninvasive system that identifies liver fibrosis in patients with NAFLD. Hepatology, Vol. 45, No. 4, (April 2007), pp. 846-854, ISSN 1527-3350

Angulo, P. \& Lindor, K. D. (2002) Non-alcoholic fatty liver disease. J.Gastroenterol.Hepatol., Vol. 17 Suppl, (February 2002), p. S186-S190, ISSN 0815-9319

Bacon, B. R., Farahvash, M. J., Janney, C. G., \& Neuschwander-Tetri, B. A. (1994) Nonalcoholic steatohepatitis: an expanded clinical entity. Gastroenterology, Vol. 107, No. 4, (October 1994), pp. 1103-1109, ISSN 7645-6 
Baumann, U. (2005). Die kindliche Fettlebererkrankung. Dtsch.Ärzteblatt, Vol. 102, No. 39, p. A2634-A2639, ISSN 0012-1207

Bellentani, S., Bedogni, G., Miglioli, L., \& Tiribelli, C. (2004). The epidemiology of fatty liver. Eur.J.Gastroenterol.Hepatol., Vol. 16, No. 11, (November 2004), pp. 1087-1093, ISSN 0954-691X

Bonekamp, S., Kamel, I., Solga, S., \& Clark, J. (2009). Can imaging modalities diagnose and stage hepatic fibrosis and cirrhosis accurately?, J.Hepatol., Vol. 50, No. 1, (January 2009), pp. 17-35, ISSN 0168-8278

Brunt, E. M. (2001). Nonalcoholic steatohepatitis: definition and pathology. Semin.Liver Dis., Vol. 21, No. 1, pp. 3-16, ISSN 0272-8087

Brunt, E. M. (2002). Alcoholic and nonalcoholic steatohepatitis. Clin.Liver Dis., Vol. 6, No. 2, (May 2002), pp. 399-420, vii, ISSN 1089-3261

Brunt, E. M. (2005a). Nonalcoholic steatohepatitis: pathologic features and differential diagnosis. Semin.Diagn.Pathol., Vol. 22, No. 4, pp. (November 2005), 330-338, ISSN $0740-2570$

Brunt, E. M. (2005b). Pathology of nonalcoholic steatohepatitis. Hepatol.Res., Vol. 33, No. 2, (October 2005), pp. 68-71, ISSN 1386-6346

Brunt, E. M. (2007). Pathology of fatty liver disease. Mod.Pathol., Vol. 20, Suppl 1, (February 2007), p. S40-S48, ISSN 0893-3952

Brunt, E. M., Janney, C. G., Di Bisceglie, A. M., Neuschwander-Tetri, B. A., \& Bacon, B. R. (1999). Nonalcoholic steatohepatitis: a proposal for grading and staging the histological lesions. Am.J.Gastroenterol., Vol. 94, No. 9, (September 1999), pp. 24672474, ISSN 0002-9270

Brunt, E. M., Neuschwander-Tetri, B. A., Oliver, D., Wehmeier, K. R., \& Bacon, B. R. (2004). Nonalcoholic steatohepatitis: histologic features and clinical correlations with 30 blinded biopsy specimens. Hum.Pathol., Vol. 35, No. 9, (September 2004), pp. 10701082, ISSN 0046-8177

Brunt, E. M., Ramrakhiani, S., Cordes, B. G., Neuschwander-Tetri, B. A., Janney, C. G., Bacon, B. R., \& Di Bisceglie, A. M. (2003). Concurrence of histologic features of steatohepatitis with other forms of chronic liver disease. Mod.Pathol., Vol. 16, No. 1, (January 2003), pp. 49-56, ISSN 0893-3952

Brunt, E. M. \& Tiniakos, D. G. (2002). Pathology of steatohepatitis. Best.Pract.Res.Clin.Gastroenterol., Vol. 16, No. 5, (October 2002), pp. 691-707, ISSN 1521-6918

Brunt, E. M. \& Tiniakos, D. G. (2005). Pathological features of NASH. Front Biosci., Vol. 10, pp. 1475-1484, ISSN 1093-9946

Burt, A. D., Mutton, A., \& Day, C. P. (1998). Diagnosis and interpretation of steatosis and steatohepatitis. Semin.Diagn.Pathol., Vol. 15, No. 4, (November 1998), pp. 246-258, ISSN 0740-2570

Caldwell, S. H., Oelsner, D. H., Iezzoni, J. C., Hespenheide, E. E., Battle, E. H., \& Driscoll, C. J. (1999). Cryptogenic cirrhosis: clinical characterization and risk factors for underlying disease. Hepatology, Vol. 29, No. 3, (March 1999), pp. 664-669, ISSN 1527-3350

Castera, L., Forns, X., \& Alberti, A. (2008). Non-invasive evaluation of liver fibrosis using transient elastography. J.Hepatol., Vol. 48, No. 5, pp. 835-847, ISSN 0168-8278 
Chalasani, N., Guo, X., Loomba, R., Goodarzi, M. O., Haritunians, T., Kwon, S., Cui, J., Taylor, K. D., Wilson, L., Cummings, O. W., Chen, Y. D., \& Rotter, J. I. (2010). Genome-wide association study identifies variants associated with histologic features of nonalcoholic Fatty liver disease. Gastroenterology, Vol. 139, No. 5, (November 2010), pp. 1567-76, 1576, ISSN 7645-6

Chitturi, S., Abeygunasekera, S., Farrell, G. C., Holmes-Walker, J., Hui, J. M., Fung, C., Karim, R., Lin, R., Samarasinghe, D., Liddle, C., Weltman, M., \& George, J. (2002). $\mathrm{NASH}$ and insulin resistance: Insulin hypersecretion and specific association with the insulin resistance syndrome. Hepatology, Vol. 35, No. 2, (February 2002), pp. 373-379, ISSN 1527-3350

Church, T. S., Kuk, J. L., Ross, R., Priest, E. L., Biltoft, E., \& Blair, S. N. (2006). Association of cardiorespiratory fitness, body mass index, and waist circumference to nonalcoholic fatty liver disease. Gastroenterology, Vol. 130, No. 7, (June 2006), pp. 2023-2030, ISSN 7645-6

Cortez-Pinto, H., de Moura, M. C., \& Day, C. P. (2006). Non-alcoholic steatohepatitis: from cell biology to clinical practice. J.Hepatol., Vol. 44, No. 1, (January 2006), pp. 197-208, ISSN 0168-8278

Dancygier, H. (2006). Pathogenese und Therapie der nichtalkoholischen Fettlebererkrankungen. Dtsch.Ärzteblatt, Vol. 103, No. 19, (12 May 2006), pp. A1301A1307, ISSN 0012-1207

Day, C. P. (2002). Pathogenesis of steatohepatitis. Best.Pract.Res.Clin.Gastroenterol., Vol. 16, No. 5, (October 2002), pp. 663-678, ISSN 1521-6918

Day, C. P. (2006). Non-alcoholic fatty liver disease: current concepts and management strategies. Clin.Med., Vol. 6, No. 1, (January 2006), pp. 19-25, ISSN 1473-4893

Day, C. P. \& James, O. F. (1998). Steatohepatitis: a tale of two "hits"?. Gastroenterology, Vol. 114, No. 4, (April 1998), pp. 842-845, ISSN 7645-6

DeLeve, L. D., Shulman, H. M., \& McDonald, G. B. (2002). Toxic injury to hepatic sinusoids: sinusoidal obstruction syndrome (veno-occlusive disease). Semin.Liver Dis., Vol. 22, No. 1, (February 2002), pp. 27-42, ISSN 0272-8087

Dufour, J. F. \& Oneta, C. M. (2004). Alcoholic and non-alcoholic steatohepatitis. Ther.Umsch., Vol. 61, No. 8, (August 2004), pp. 505-512, ISSN 0040-5930

Duvnjak, M., Lerotic, I., Barsic, N., Tomasic, V., Virovic, J. L., \& Velagic, V. (2007). Pathogenesis and management issues for non-alcoholic fatty liver disease. World J.Gastroenterol., Vol. 13, No. 34, (14 September 2007), pp. 4539-4550, ISSN 1007-9327

Edmison, J. \& McCullough, A. J. (2007). Pathogenesis of non-alcoholic steatohepatitis: human data. Clin.Liver Dis., Vol. 11, No. 1, (February 2007), pp. 75-104, ISSN 10893261

Falck-Ytter, Y., Younossi, Z. M., Marchesini, G., \& McCullough, A. J. (2001). Clinical features and natural history of nonalcoholic steatosis syndromes. Semin.Liver Dis., Vol. 21, No. 1, pp. 17-26, ISSN 0272-8087

Farrell, G. C. \& Larter, C. Z. (2006). Nonalcoholic fatty liver disease: from steatosis to cirrhosis. Hepatology, Vol. 43, No. 2 Suppl 1, (February 2006), p. S99-S112, ISSN 1527-3350

Friedrich-Rust, M., Ong, M. F., Martens, S., Sarrazin, C., Bojunga, J., Zeuzem, S., \& Herrmann, E. (2008). Performance of transient elastography for the staging of liver 
fibrosis: a meta-analysis. Gastroenterology, Vol. 134, No. 4, (April 2008), pp. 960-974, ISSN 7645-6

Gentilucci, U. V., Santini, D., Vincenzi, B., Fiori, E., Picardi, A., \& Tonini, G. (2006). Chemotherapy-induced steatohepatitis in colorectal cancer patients. J.Clin.Oncol., Vol. 24, No. 34, (1 December 2006), pp. 5467-5468, ISSN 0732-183X

Gramlich, T., Kleiner, D. E., McCullough, A. J., Matteoni, C. A., Boparai, N., \& Younossi, Z. M. (2004). Pathologic features associated with fibrosis in nonalcoholic fatty liver disease. Hum.Pathol., Vol. 35, No. 2, (February 2004), pp. 196-199, ISSN 0046-8177

Harrison, S. A., Torgerson, S., \& Hayashi, P. H. (2003). The natural history of nonalcoholic fatty liver disease: a clinical histopathological study. Am.J.Gastroenterol., Vol. 98, No. 9, (September 2003), pp. 2042-2047, ISSN 0002-9270

Hubscher, S. G. (2004). Role of liver biopsy in the assessment of non-alcoholic fatty liver disease. Eur.J.Gastroenterol.Hepatol., Vol. 16, No. 11, (November 2004), pp. 11071115, ISSN 0954-691X

Joy, D., Thava, V. R., \& Scott, B. B. (2003). Diagnosis of fatty liver disease: is biopsy necessary?, Eur.J.Gastroenterol.Hepatol., vol. 15, no. 5, (May 2003), pp. 539-543, ISSN 0954-691X

Kacerovsky, M. \& Roden, M. (2007). Nichtalkoholische Fettleber. Diabetologe, Vol. 3, pp. 176183, ISSN 1860-9716

Karoui, M., Penna, C., min-Hashem, M., Mitry, E., Benoist, S., Franc, B., Rougier, P., \& Nordlinger, B. (2006). Influence of preoperative chemotherapy on the risk of major hepatectomy for colorectal liver metastases. Ann.Surg., Vol. 243, No. 1, (January 2006), pp. 1-7, ISSN 0003-4932

Kleiner, D. E., Brunt, E. M., Van, N. M., Behling, C., Contos, M. J., Cummings, O. W., Ferrell, L. D., Liu, Y. C., Torbenson, M. S., Unalp-Arida, A., Yeh, M., McCullough, A. J., \& Sanyal, A. J. (2005). Design and validation of a histological scoring system for nonalcoholic fatty liver disease. Hepatology, Vol. 41, No. 6, (June 2005), pp. 13131321, ISSN 1527-3350

Lackner, C., Gogg-Kamerer, M., Zatloukal, K., Stumptner, C., Brunt, E. M., \& Denk, H. (2008). Ballooned hepatocytes in steatohepatitis: the value of keratin immunohistochemistry for diagnosis. J.Hepatol., Vol. 48, No. 5, (May 2008), pp. 821828, ISSN 0168-8278

Ludwig, J., McGill, D. B., \& Lindor, K. D. (1997). Review: nonalcoholic steatohepatitis. J.Gastroenterol.Hepatol., Vol. 12, No. 5, (May 1997), pp. 398-403, ISSN 0815-9319

Ludwig, J., Viggiano, T. R., McGill, D. B., \& Oh, B. J. (1980). Nonalcoholic steatohepatitis: Mayo Clinic experiences with a hitherto unnamed disease. Mayo Clin.Proc., Vol. 55, No. 7, (July 1980), pp. 434-438, ISSN 0025-6196

Matteoni, C. A., Younossi, Z. M., Gramlich, T., Boparai, N., Liu, Y. C., \& McCullough, A. J. (1999). Nonalcoholic fatty liver disease: a spectrum of clinical and pathological severity. Gastroenterology, Vol. 116, No. 6, (June 1999), pp. 1413-1419, ISSN 7645-6

Medina, J., Fernandez-Salazar, L. I., Garcia-Buey, L., \& Moreno-Otero, R. (2004). Approach to the pathogenesis and treatment of nonalcoholic steatohepatitis. Diabetes Care, Vol. 27, No. 8, (August 2004), pp. 2057-2066, ISSN 0149-5992

Mendez-Sanchez, N., Arrese, M., Zamora-Valdes, D., \& Uribe, M. (2007). Current concepts in the pathogenesis of nonalcoholic fatty liver disease. Liver Int., Vol. 27, No. 4, (May 2007), pp. 423-433, ISSN 1478-3223 
Mendler, M. H., Kanel, G., \& Govindarajan, S. ( 2005). Proposal for a histological scoring and grading system for non-alcoholic fatty liver disease. Liver Int., Vol. 25, No. 2, (April 2005), pp. 294-304, ISSN 1478-3223

Mofrad, P., Contos, M. J., Haque, M., Sargeant, C., Fisher, R. A., Luketic, V. A., Sterling, R. K., Shiffman, M. L., Stravitz, R. T., \& Sanyal, A. J. (2003). Clinical and histologic spectrum of nonalcoholic fatty liver disease associated with normal ALT values. Hepatology, Vol. 37, No. 6, (June 2003), pp. 1286-1292, ISSN 1527-3350

Nakano, H., Oussoultzoglou, E., Rosso, E., Casnedi, S., Chenard-Neu, M. P., Dufour, P., Bachellier, P., \& Jaeck, D. (2008). Sinusoidal injury increases morbidity after major hepatectomy in patients with colorectal liver metastases receiving preoperative chemotherapy. Ann.Surg., Vol. 247, No. 1, (January 2008), pp. 118-124, ISSN 00034932

Neuschwander-Tetri, B. A. (2002). Evolving pathophysiologic concepts in nonalcoholic steatohepatitis. Curr.Gastroenterol.Rep., vol. 4, no. 1, (February 2002), pp. 31-36, ISSN 1522-8037

Neuschwander-Tetri, B. A. \& Caldwell, S. H. (2003). Nonalcoholic steatohepatitis: summary of an AASLD Single Topic Conference. Hepatology, Vol. 37, No. 5, (May 2003), pp. 1202-1219, ISSN 1527-3350

Nocito, A., El-Badry, A. M., \& Clavien, P. A. (2006). When is steatosis too much for transplantation?, J.Hepatol., vol. 45, no. 4, (October 2006), pp. 494-499, ISSN 01688278

Nordlinger, B., Van, C. E., Rougier, P., Kohne, C. H., Ychou, M., Sobrero, A., Adam, R., Arvidsson, D., Carrato, A., Georgoulias, V., Giuliante, F., Glimelius, B., Golling, M., Gruenberger, T., Tabernero, J., Wasan, H., \& Poston, G. (2007). Does chemotherapy prior to liver resection increase the potential for cure in patients with metastatic colorectal cancer? A report from the European Colorectal Metastases Treatment Group. Eur.J.Cancer, Vol. 43, No. 14, (September 2007), pp. 2037-2045, ISSN 09598049

Oneta, C. M. \& Dufour, J. F. (2003). Diagnostik, Prognose und therapeutische Möglichkeiten der nicht-alkoholischen Fettlebererkrankung. Schweiz Med Forum, Vol. 37, pp. 862868, ISSN 0036-7672

Papandreou, D., Rousso, I., \& Mavromichalis, I. (2007). Update on non-alcoholic fatty liver disease in children. Clin.Nutr., Vol. 26, No. 4, (August 2007), pp. 409-415, ISSN 0261-5614

Petersen, K. F., Dufour, S., Hariri, A., Nelson-Williams, C., Foo, J. N., Zhang, X. M., Dziura, J., Lifton, R. P., \& Shulman, G. I. (2010). Apolipoprotein C3 gene variants in nonalcoholic fatty liver disease. N.Engl.J.Med., Vol. 362, No. 12, (25 March 2010), pp. 1082-1089, ISSN 0028-4793

Rashid, M. \& Roberts, E. A. (2000). Nonalcoholic steatohepatitis in children. J.Pediatr.Gastroenterol.Nutr., Vol. 30, No. 1, (January 2000), pp. 48-53, ISSN 0277-2116

Ratziu, V., Charlotte, F., Heurtier, A., Gombert, S., Giral, P., Bruckert, E., Grimaldi, A., Capron, F., \& Poynard, T. (2005). Sampling variability of liver biopsy in nonalcoholic fatty liver disease. Gastroenterology, Vol. 128, No. 7, (June 2005), pp. 1898-1906, ISSN 7645-6

Reid, A. E. (2001). Nonalcoholic steatohepatitis. Gastroenterology, Vol. 121, No. 3, (September 2001), pp. 710-723, ISSN 7645-6 
Roberts, E. A. (2002). Steatohepatitis in children. Best.Pract.Res.Clin.Gastroenterol., Vol. 16, No. 5, (October 2002), pp. 749-765, ISSN 1521-6918

Roberts, E. A. (2007). Non-alcoholic steatohepatitis in children. Clin.Liver Dis., Vol. 11, No. 1, (February 2007), pp. 155-72, ISSN 1089-3261

Rousselet, M. C., Michalak, S., Dupre, F., Croue, A., Bedossa, P., Saint-Andre, J. P., \& Cales, P. (2005). Sources of variability in histological scoring of chronic viral hepatitis. Hepatology, Vol. 41, No. 2, (February 2005), pp. 257-264, ISSN 1527-3350

Sanyal, A. J., Banas, C., Sargeant, C., Luketic, V. A., Sterling, R. K., Stravitz, R. T., Shiffman, M. L., Heuman, D., Coterrell, A., Fisher, R. A., Contos, M. J., \& Mills, A. S. (2006). Similarities and differences in outcomes of cirrhosis due to nonalcoholic steatohepatitis and hepatitis C. Hepatology, vol. 43, no. 4, (April 2006), pp. 682-689, ISSN 1527-3350

Schwimmer, J. B. (2007). Definitive diagnosis and assessment of risk for nonalcoholic fatty liver disease in children and adolescents. Semin.Liver Dis., Vol. 27, No. 3, (August 2007), pp. 312-318, ISSN 0272-8087

Schwimmer, J. B., Behling, C., Newbury, R., Deutsch, R., Nievergelt, C., Schork, N. J., \& Lavine, J. E. (2005). Histopathology of pediatric nonalcoholic fatty liver disease. Hepatology, Vol. 42, No. 3, (September 2005), pp. 641-649, ISSN 1527-3350

Sonsuz, A., Basaranoglu, M., \& Ozbay, G. (2000). Relationship between aminotransferase levels and histopathological findings in patients with nonalcoholic steatohepatitis. Am.J.Gastroenterol., Vol. 95, No. 5, (May 2000), pp. 1370-1371, ISSN 0002-9270

Strassburg, C. P. \& Manns, M. P. (2006). Approaches to liver biopsy techniques--revisited. Semin.Liver Dis., Vol. 26, No. 4, (November 2006), pp. 318-327, ISSN 0272-8087

Tannapfel, A., Geissler, F., Witzigmann, H., Hauss, J., \& Wittekind, C. (2001). Analysis of liver allograft rejection related genes using cDNA-microarrays in liver allograft specimen. Transplant.Proc., Vol. 33, No. 7-8, (November 2001), pp. 3283-3284, ISSN 0041-1345

Tannapfel, A. \& Reinacher-Schick, A. (2008). Chemotherapy associated hepatotoxicity in the treatment of advanced colorectal cancer (CRC). Z.Gastroenterol., Vol. 46, No. 5, (May 2008), pp. 435-440, ISSN 0044-2771

Tannapfel, A., Denk, H., Dienes, H.P., Langner, C., Schirmacher, P., Trauner, M., FlottRahmel, B. (2009). Histopathological Diagnosis of Non-alcoholic and Alcoholic Fatty Liver Disease, In: AWMF online, 01 November 2009, Available from: http://www.awmf.org/leitlinien/detail/1l/035-004.html

Targher, G., Bertolini, L., Rodella, S., Zoppini, G., Scala, L., Zenari, L., \& Falezza, G. (2006). Associations between plasma adiponectin concentrations and liver histology in patients with nonalcoholic fatty liver disease. Clin.Endocrinol.(Oxf), Vol. 64, No. 6, (June 2006), pp. 679-683, ISSN 0300-0664

Teli, M. R., James, O. F., Burt, A. D., Bennett, M. K., \& Day, C. P. (1995). The natural history of nonalcoholic fatty liver: a follow-up study. Hepatology, Vol. 22, No. 6, (December 1995), pp. 1714-1719, ISSN 1527-3350

Valenti, L., Alisi, A., Galmozzi, E., Bartuli, A., Del Menico, B., Alterio, A., Dongiovanni, P., Fargion, S., \& Nobili, V. (2010). I148M patatin-like phospholipase domaincontaining 3 gene variant and severity of pediatric nonalcoholic fatty liver disease. Hepatology, Vol. 52, No. 4, (October 2010), pp. 1274-1280, ISSN 1527-3350 
Vauthey, J. N., Pawlik, T. M., Ribero, D., Wu, T. T., Zorzi, D., Hoff, P. M., Xiong, H. Q., Eng, C., Lauwers, G. Y., Mino-Kenudson, M., Risio, M., Muratore, A., Capussotti, L., Curley, S. A., \& Abdalla, E. K. (2006). Chemotherapy regimen predicts steatohepatitis and an increase in 90-day mortality after surgery for hepatic colorectal metastases. J.Clin.Oncol., Vol. 24, No. 13, (1 May 2006), pp. 2065-2072, ISSN 0732-183X

Wieckowska, A., McCullough, A. J., \& Feldstein, A. E. (2007). Noninvasive diagnosis and monitoring of nonalcoholic steatohepatitis: present and future. Hepatology, Vol. 46, No. 2, pp. 582-589, ISSN 1527-3350

Wieckowska, A., Zein, N. N., Yerian, L. M., Lopez, A. R., McCullough, A. J., \& Feldstein, A. E. (2006). In vivo assessment of liver cell apoptosis as a novel biomarker of disease severity in nonalcoholic fatty liver disease. Hepatology, Vol. 44, No. 1, (July 2006), pp. 27-33, ISSN 1527-3350

Williams, C. D., Stengel, J., Asike, M. I., Torres, D. M., Shaw, J., Contreras, M., Landt, C. L., \& Harrison, S. A. (2011). Prevalence of nonalcoholic fatty liver disease and nonalcoholic steatohepatitis among a largely middle-aged population utilizing ultrasound and liver biopsy: a prospective study. Gastroenterology, Vol. 140, No. 1, (January 2011), pp. 124-131, ISSN 7645-6

Younossi, Z. M., Jarrar, M., Nugent, C., Randhawa, M., Afendy, M., Stepanova, M., Rafiq, N., Goodman, Z., Chandhoke, V., \& Baranova, A. (2008). A Novel Diagnostic Biomarker Panel for Obesity-related Nonalcoholic Steatohepatitis (NASH). Obes.Surg., Vol 18, No. 11, (24 May 2008), pp1430-1437, ISSN 0960-8923

Zivkovic, A. M., German, J. B., \& Sanyal, A. J. (2007).Comparative review of diets for the metabolic syndrome: implications for nonalcoholic fatty liver disease. Am.J.Clin.Nutr., Vol. 86, No. 2, (August 2007), pp. 285-300, ISSN 0002-9165 


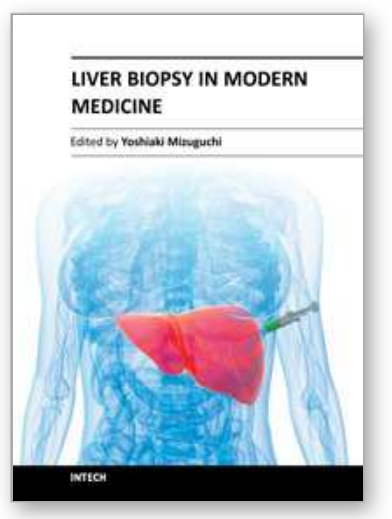

\author{
Liver Biopsy in Modern Medicine \\ Edited by Dr. Yoshiaki Mizuguchi
}

ISBN 978-953-307-883-0

Hard cover, 378 pages

Publisher InTech

Published online 10, October, 2011

Published in print edition October, 2011

Liver biopsy, first performed by Paul Ehrlich in 1883, remains an important diagnostic procedure for the management of hepatobiliary disorders and the candidate/donated organ for transplantation. The book "Liver biopsy in Modern Medicine" comprises 21 chapters covering the various aspects of the biopsy procedure in detail and provides an up-to-date insightful coverage to the recent advances in the management of the various disorders with liver biospy. This book will keep up with cutting edge understanding of liver biopsy to many clinicians, physicians, scientists, pharmaceutics, engineers and other experts in a wide variety of different disciplines.

\title{
How to reference
}

In order to correctly reference this scholarly work, feel free to copy and paste the following:

Andrea Tannapfel and Berenike Flott-Rahmel (2011). Histopathological Diagnosis of Non-Alcoholic and Alcoholic Fatty Liver Disease, Liver Biopsy in Modern Medicine, Dr. Yoshiaki Mizuguchi (Ed.), ISBN: 978-953307-883-0, InTech, Available from: http://www.intechopen.com/books/liver-biopsy-in-modernmedicine/histopathological-diagnosis-of-non-alcoholic-and-alcoholic-fatty-liver-disease

\section{INTECH}

open science | open minds

\section{InTech Europe}

University Campus STeP Ri Slavka Krautzeka 83/A 51000 Rijeka, Croatia Phone: +385 (51) 770447

Fax: +385 (51) 686166 www.intechopen.com

\section{InTech China}

Unit 405, Office Block, Hotel Equatorial Shanghai No.65, Yan An Road (West), Shanghai, 200040, China 中国上海市延安西路65号上海国际贵都大饭店办公楼 405 单元 Phone: +86-21-62489820

Fax: $+86-21-62489821$ 
(C) 2011 The Author(s). Licensee IntechOpen. This is an open access article distributed under the terms of the Creative Commons Attribution 3.0 License, which permits unrestricted use, distribution, and reproduction in any medium, provided the original work is properly cited. 